\title{
$\mathrm{NFC}$ 를 활용한 자동차 내비게이션 시스템의 구현
}

\author{
신예진 · 설순욱
}

\section{An Implementation of Car Navigation System using NFC}

\section{Yejin Shin · Soonuk Seol*}

School of Electrical, Electronics \& Communication Engineering, Korea University of Technology \& Education, Cheonan 330-708, Korea

\section{요 약}

현재 사용되는 내비게이션 단말기의 문제점은 목적지를 설정하기 위하여 사용자에게 많은 입력을 요구한다는 것 이다. 이는 차량 이동 시 운전에 대한 집중력 저하로 이어져 교통사고를 유발하는 원인이 되기도 한다. 본 논문은 이 러한 불편을 보완하기 위해 $\mathrm{NFC}$ 를 활용하여 사용자 입력을 최소화시켜 내비게이션의 사용을 편리하고 안전하게 하 는 시스템을 설계하고 구현한다. 스마트폰을 내비게이션의 NFC 리더에 터치하는 간단한 동작만으로 목적지의 정보 를 입력할 수 있도록 설계하고, 설계한 시스템을 어플리케이션을 통해 구현한다. 또한 기존 내비게이션 제어 방법과 의 비교를 통해 본 논문에서 구현한 시스템의 효과를 검증한다.

\section{ABSTRACT}

One of problems in car navigation systems is that a number of inputs are required for a directions search. This may even causes a car accident due to poor concentration while driving. In order to solve the issue we design and implement a safe and easy-to-use car navigation system which allows a driver to look up directions with just a single tap. Our smartphone app creates an NFC tag by deriving location information from a text, voice, GPS, and so on. The driver can then get the directions by just tapping a phone or card with the Tag on the navigation system. We show the feasibility and effectiveness of our system by comparing our implementation with the existing car navigation systems.

키워드 : RFID, NFC, 내비게이션, 스마트폰, 어플리케이션, 데이터베이스

Key word : RFID, NFC, Navigation, Smartphone, Application, Database

접수일자 : 2014. 02. 19 심사완료일자 : 2014. 03. 27 게재확정일자 : 2014. 04. 07

* Corresponding Author Soonuk Seol(E-mail:suseol@koreatech.ac.kr, Tel:+82-41-560-1426)

School of Electrical, Electronics \& Communication Engineering, Korea University of Technology \& Education, Cheonan 330-708, Korea 


\section{I. 서 론}

일반적으로, 차량 내에 설치된 내비게이션 단말기는 사용자에 의해 입력된 주소나 전화번호, 명칭 등의 목 적지 정보를 이용하여 사용자의 위치로부터 목적지까 지의 경로를 안내한다. 이러한 편리성에 의해 내비게이 션 단말기는 이제 운전을 할 때 없어서는 안 될 필수품 이 되었다.

그러나 많은 운전자들은 운전 중에 내비게이션 단말 기를 조작하는 데 불편함을 토로한다. 내비게이션 단말 기의 목적지 입력을 위한 터치가 번거로워 꽤 많은 시 간이 소요되기 때문이다. 기존의 차량용 내비게이션으 로 경로를 검색하기 위해서는 크게 두 가지 방법을 사 용하는데, 이는 사용자가 직접 화면을 터치하여 목적지 를 입력하는 방식과 내비게이션 자체의 음성검색 기능 을 통해 입력하는 방식이다. 하지만 직접 화면을 터치 하기에는 목적지 설정 시 사용자가 여러 차례의 입력과 정을 거쳐야 하며, 내비게이션 단말기가 운전석과 일정 거리 떨어져있어 입력 시 오탈자가 많이 발생한다. 따 라서 여러 차례의 삭제와 재입력 과정을 거치다 보면 원하는 목적지를 입력하는 데 시간이 다소 소요된다. 또한 음성검색 기능 역시 차량 자체 소음과 주변 소음 으로 인해 음성 인식률이 낮아 활용성이 떨어진다. 이 때문에 차량 이동 중에 목적지 정보를 내비게이션 단말 기에 입력하는 것은 운전에 대한 집중력 저하를 야기하 여 교통사고를 유발하는 원인이 된다.

이 논문은 NFC 기술을 활용하여 내비게이션 목적지 입력의 편리성과 안전성을 증대시키는 시스템을 설계 및 구현한다. 2장에서는 NFC 기술과 NFC를 활용한 연 구 사례를 분석하고 3장에서는 본 논문의 내비게이션 시스템의 설계 및 구현 내용을 설명한다. 4장에서는 기 존 내비게이션 제어 방법과의 비교를 통해 본 논문에서 구현한 시스템의 효과를 분석하고 마지막으로 5장에서 는 결론을 제시한다.

\section{ㅍ. 본 론}

\subsection{NFC 기술}

$\mathrm{NFC}($ Near Field Communication)는 전자태그(RFID) 기술을 확장한 것으로, $13.56 \mathrm{MHz}$ 주파수 대역을 사용
하는 비접촉식 근거리 무선 통신 기술이다. $10 \mathrm{~cm}$ 이내 의 가까운 거리에서 인식하기 때문에 통신거리가 짧고 보안이 우수하다는 특징이 있다. 또한 널리 사용되고 있는 근거리 무선 통신 기술 중 하나인 블루투스와 비 교했을 때, 접속 방법이 간단하고 정확도가 높다는 장 점이 있다.

$\mathrm{NFC}$ 는 모바일기기, 특히 스마트폰과의 융합을 통해 단말 간 데이터통신을 제공할 수 있을 뿐만 아니라 기 존의 RFID와의 상호호환성을 제공한다. 최근 $\mathrm{NFC}$ 를 탑재한 스마트폰의 급격한 확산에 힘입어[1] 전화번호 나 이미지 등을 손쉽게 공유하고 결제수단으로도 사용 할 수 있어 편리성과 효율성이 더욱 높아졌다.

$\mathrm{NFC}$ 를 통해 데이터를 송수신하기 위해서는 단말을 태그에 갖다 대거나, 두 개의 단말을 가까이 두면 된다. 단말을 태그에 갖다 대는 경우, 태그에 데이터를 입력 하거나 태그에 있는 데이터를 읽어 들이는 Reader/ Writer Mode로 동작한다. 그리고 두 단말 간 통신의 경우에는 Peer-to-Peer Mode로 동작하여 양방향 통신 을 하거나, 하나의 단말이 태그로 동작하는 Card Emulation Mode로 사용할 수도 있다. 이처럼 NFC 포럼 [2]에서는 NFC 동작 방식을 다음 표 1 과 같이 세 가지 로 분류한다.

\section{표 1. NFC 동작 방식}

Table. 1 NFC Operation Modes

\begin{tabular}{|c|c|c|}
\hline 동작방식 & 설 명 & 응용 분야 \\
\hline \hline $\begin{array}{c}\text { Reader/Writer } \\
\text { Mode }\end{array}$ & $\begin{array}{c}\text { 단말기가 태그를 } \\
\text { 인식하여, 태그에 } \\
\text { 데이터를 읽거나 쓰는 } \\
\text { 동작이 가능 }\end{array}$ & 스마트포스터 \\
\hline $\begin{array}{c}\text { Peer-to-Peer } \\
\text { Mode }\end{array}$ & $\begin{array}{c}\text { 단말기 끼리 데이터를 } \\
\text { 주고받을 수 있음 }\end{array}$ & $\begin{array}{c}\text { 연락처 교환, } \\
\text { 이미지 공유 }\end{array}$ \\
\hline $\begin{array}{c}\text { Card Emulation } \\
\text { Mode }\end{array}$ & $\begin{array}{c}\text { 단말기를 태그로 사용 } \\
\text { 가능 }\end{array}$ & $\begin{array}{c}\text { 스마트카드(교통 } \\
\text { 카드, 신용카드) }\end{array}$ \\
\hline
\end{tabular}

\subsection{NFC를 활용한 연구 사례}

$\mathrm{NFC}$ 는 널리 사용되고 있는 근거리 무선 통신 기술 중에서도 접속 방법이 간단하고 정확도가 높다는 장 점을 가지고 있다. 또한 2012년 이후 출시되는 대부 분의 스마트폰에서 $\mathrm{NFC}$ 기능을 지원하면서 $\mathrm{NFC}$ 의 편리성과 효율성이 더욱 증가하였다. 이에 따라 NFC 를 활용한 새로운 시스템들이 많이 제안되고 있다. 
이번 장에서는 기존의 $\mathrm{NFC}$ 와 관련된 연구들을 분석 해보았다.

$\mathrm{NFC}$ 와 관련된 연구는 크게 $\mathrm{NFC}$ 를 활용해 결제, 정 보 교환, 인증 등의 응용 시스템을 만든 연구, $\mathrm{NFC}$ 를 더 효과적으로 활용하기 위한 기반시스템을 제안한 연구, 그 외 NFC의 동향 및 표준화 활동, 전략과 관련된 연구 등으로 분류할 수 있다.

응용 시스템 중 결제 사례로는 무인화 마켓을 구현하 기 위한 모바일 NFC 결제 시스템[3], NFC를 활용한 홈 쇼핑 결제 시스템 설계[4], 안드로이드 기반의 NFC 쇼 핑 어플리케이션 시스템[5] 등이 있다. 그리고 정보 교 환 사례로는 동적 업데이트를 지원하는 NFC 전자명함 시스템 설계[6], Cloud 환경에서 $\mathrm{NFC}$ 를 활용한 정보 공 유 서비스[7], NFC를 이용한 헬스장 관리 시스템[8] 등 이 있다. 인증 사례로는 NFC 태그를 이용한 사용자 인 증기반의 모바일 프린팅 시스템[9], NFC를 이용한 차 량 스마트키 제안[10], $\mathrm{NFC}$ 를 활용한 출결관리 시스템 구현[11] 등이 있다.

기반시스템 관련 연구사례로는 NFC를 활용한 능동 형 인증 방법[12], NFC 기반 모바일 서비스 보안 위협 및 대책[13], 비대칭 암호화를 지원하는 유연한 아키텍 처와 보안 가능한 NFC 태그[14] 등이 있으며, 그 외 사 례로는 무선근접통신(NFC) 소개와 군 적용 방안[15], $\mathrm{NFC}$ 시장 현황 및 활성화 방안 연구[16], 그리고 모바 일 RFID 기술 표준화 활동 및 전략[17] 등이 있다.

이런 연구들은 주로 $\mathrm{NFC}$ 를 활용하여 기존의 시스템 이나 서비스를 개선하기위한 모델을 제안한 것이다. 그 러나 대부분 모델제안에 그치고 실제 구현 혹은 시뮬레 이션을 통한 검증이 부족했다. 본 논문은 제안한 시스 템을 실제로 구현함으로써 새롭게 설계한 시스템의 실 현 가능성을 검증하고, 기존 시스템과의 비교를 통해 개선점을 분석하고자 한다.

\section{NFC를 활용한 내비게이션 시스템 설계 및 구현}

\section{1. 시스템 구조}

다음 그림 1 은 본 논문에서 구현한 시스템의 기본 구 조이다. 본 시스템은 크게 차량용 내비게이션과 운전자 용 스마트폰 어플리케이션, 카드 형태의 NFC 태그로
나눌 수 있다. 차량용 내비게이션은 NFC 리더기가 포 함되어 있으며, 운전자의 스마트폰은 NFC 기능이 탑재 되어있다.

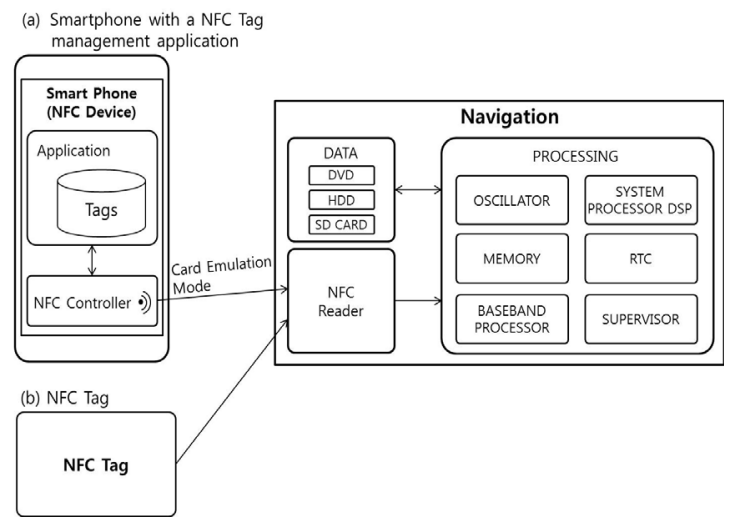

그림 1. 시스템 구성도

Fig. 1 System Architecture

운전자는 자신의 스마트폰 어플리케이션에 목적지 정보가 담긴 태그를 여러 개 저장한다. 이 때 목적지 정보는 상호명과 같은 명칭이나 주소 등 여러 가지 형 태로 저장이 가능하다. 운전자가 내비게이션 경로 안 내 기능을 사용하고자 할 때에는 어플리케이션에서 원하는 태그를 선택하여 스마트폰을 내비게이션의 $\mathrm{NFC}$ 리더기에 터치한다. 그러면 NFC를 통해 스마트 폰 어플리케이션에 저장되어 있던 목적지 정보가 내 비게이션으로 전송되어 손쉽게 경로 안내를 받을 수 있다. 이러한 방식으로 작동하는 방법이 그림 1의 (a) 에 해당한다.

이처럼 본 논문에서 구현한 시스템에서는 스마트폰 자체를 목적지 정보를 담은 하나의 태그로 만든다. $\mathrm{NFC}$ 태그가 된 스마트폰을 내비게이션 단말기의 NFC 리더에 갖다 대는 방식이다. 이는 NFC 동작 방식 중 Card Emulation Mode에 해당한다. 이때 NFC 태그로는 스마트폰은 물론 일반적인 NFC 태그도 사용 가능하 며, 이 방식은 그림 1 의 (b)에 나타내었다. 목적지 정보 가 저장된 태그를 NFC 리더에 갖다 대면, 내비게이션 은 NFC를 통해 태그 정보를 수신하여 바로 경로 안내 를 받을 수 있도록 한 것이다. 이러한 카드 형태의 NFC 태그는 식당이나 관광지 등에서 태그를 나눠준다면 홍 보용으로도 사용할 수 있는 등의 경제적인 효과를 기 
대할 수 있다. 그림 2는 홍보용 NFC 태그의 활용 예시 이다.

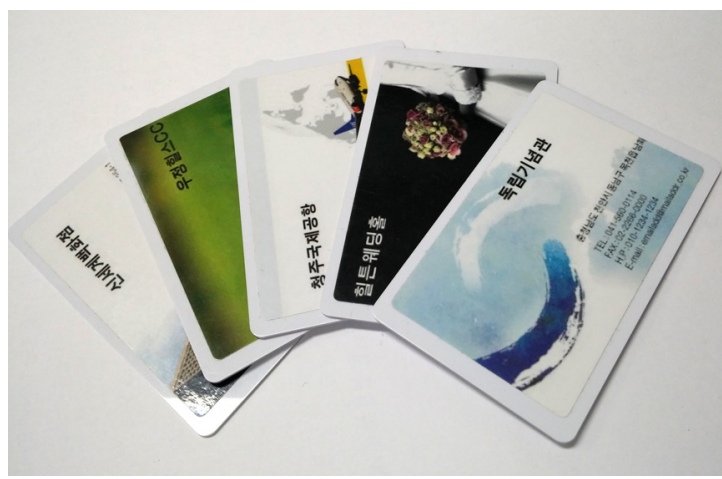

그림 2. 명함 형태의 NFC 태그

Fig. 2 NFC Tag as business card

\section{2. 어플리케이션 설계 및 구현}

제안한 어플리케이션은 목적지 정보를 저장하기 위 해 다양한 태그 제작 방법을 제공한다. 먼저 기본적으 로 기존의 내비게이션처럼 스마트폰에서 직접 주소나 상호명 등의 명칭을 직접 입력하는 방법을 제공한다. 또한 스마트폰 음성인식 기능을 사용하여 입력하는 방 법도 있다. 그리고 스마트폰으로 촬영한 사진에 저장 되어있는 사진촬영 위치 정보를 입력하는 방법이나, GPS 정보를 통해 현재 위치의 위·경도 정보를 주소로 변환하여 입력하는 방법도 사용할 수 있다. 또한 NFC 동작 방식 중 Reader Mode를 사용하여 카드 형태의 $\mathrm{NFC}$ 태그를 읽어 들여 어플리케이션에 저장하는 방법 도 있다.

카드 형태의 태그는 어플리케이션이 없어도 내비 게이션의 NFC 리더에 터치하면 길안내를 받을 수 있 지만, 카드 형태의 태그가 여러 장일 경우, 이를 관리 하기에는 어려움이 따른다. 따라서 어플리케이션을 통해 하나의 앱으로 여러 개의 태그를 효율적으로 관 리할 수 있도록 한 것이다. 이와 같은 방법들은 차에 탑승하기 전이라도 이동할 목적지가 결정되면 언제 든지 어디서나 쉽게 입력이 가능하다는 것이 특징이 다. 아래 그림 3은 어플리케이션을 통해 목적지 정보 를 담고 있는 NFC 태그를 제작하는 방법에 대한 구성 도이다.

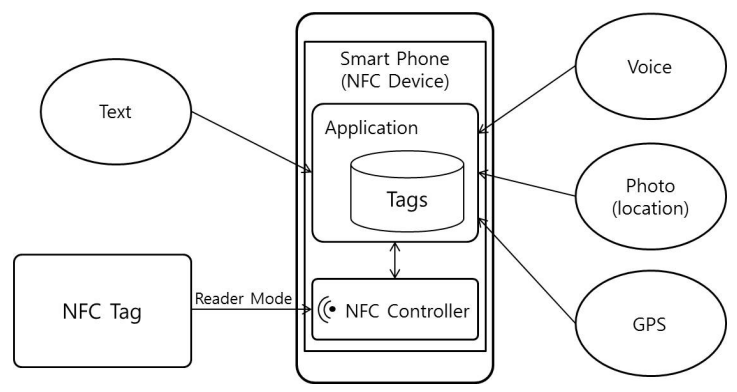

그림 3. NFC 태그의 제작

Fig. 3 Creation of NFC Tags

그림 4는 실제 어플리케이션으로 구현한 화면이다. (a)는 아래쪽의 버튼들을 통해 입력 방법을 선택하여 목 적지의 주소를 입력한 화면이다. (b)는 어플리케이션에 저장된 태그들을 보여주는 화면이다. 위쪽에서 태그 목 록들을 좌우로 스크롤하여 확인할 수 있고, 목록에서 선택한 태그는 화면 중앙에 태그의 세부 정보와 함께 출력된다.

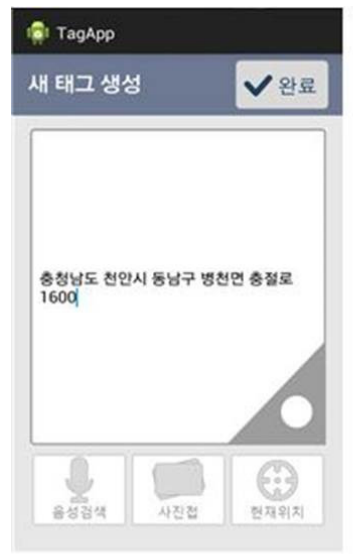

(a)

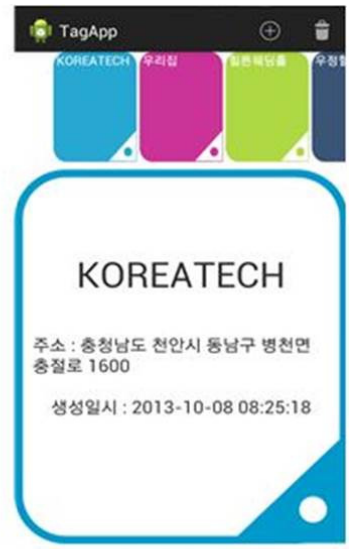

(b)
그림 4. NFC Tag 관리 어플리케이션 (a) 목적지 입력 화면 (b) 저장된 태그 정보

Fig. 4 NFC Tag management application (a) screen of a destination input (b) stored tag information

그림 5는 본 연구를 통해 구현한 어플리케이션을 사 용하여 내비게이션의 경로 안내를 받기 위해 실제로 $\mathrm{NFC}$ 터치를 하는 장면이다. 구현을 위해 내비게이션으 로는 갤럭시 노트1 단말기를 사용하였다. 그리고 내비 게이션의 NFC 리더는 운전석에서 일정 거리 이상 떨어 
져 있으면 사용이 불편하기 때문에 운전자 편의를 위해 핸들 내부에 설치하였다. 기존의 GPS나 DMB에서 연 장선을 통해 외장 안테나를 활용한 방식과 유사하다.

어플리케이션에서 원하는 목적지를 선택하고 핸들 에 갖다 대면 핸들 내부의 NFC 리더를 통해 내비게 이션으로 목적지 정보가 전송된다. 내비게이션은 전 송된 목적지로의 경로를 안내한다.

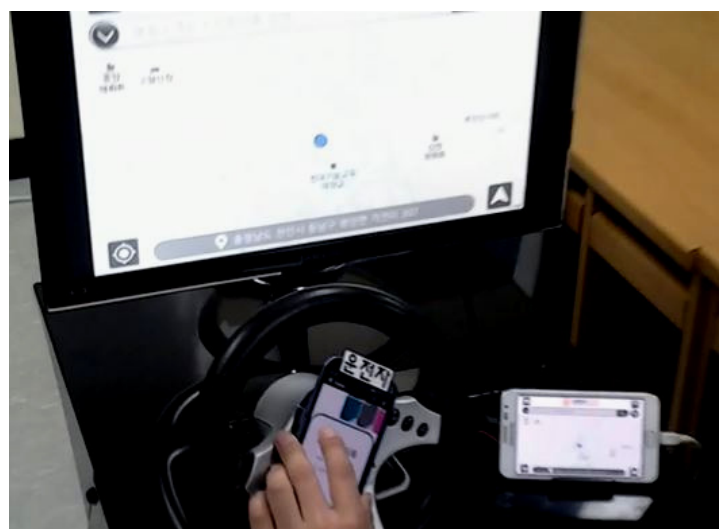

그림 5. 시연 장면

Fig. 5 Demonstration

\section{IV. 비교분석}

이번 장에서는 기존 내비게이션의 제어 방법과 비교 하여 본 논문에서 구현한 시스템의 효과를 분석하고자 한다. 현재 사용되는 내비게이션 단말기는 이용자가 직 접 찾고자 하는 목적지의 주소나 전화번호, 명칭 등을 입력하면 이용자의 위치로부터 목적지까지의 경로를 지도의 형태로 표시해주는 기능을 한다. 즉, 경로 안내 를 받기 위해서는 여러 번의 메뉴 선택 과정을 거쳐야 하는 것이다. 그런데 기존의 차량용 내비게이션 단말기 는 대부분 감압식 터치패드를 사용하고 있어서 터치 민 감도가 다소 떨어진다. 따라서 정전식 터치패드를 사용 하는 이동 단말기(스마트폰)에 비해 목적지를 입력할 때 많은 오탈자가 발생된다. 따라서 여러 차례의 입력 과정을 거치다 보면 원하는 목적지를 입력하는 데 시간 이 다소 소요된다.

아래 표 2 는 기존의 차량용 내비게이션을 통해 경로 안내를 받는 것(a)과, 본 논문에서 구현한 어플리케이션
을 사용하여 경로 안내를 받기까지의 조작 과정(b)을 비 교한 것이다. 표 2 를 통해 기존 내비게이션 조작 과정의 문제점을 쉽게 확인할 수 있다.

표 2. 경로 검색 과정 비교 (a) 기존 차량용 내비게이션 (b) 제안 시스템

Table. 2 Comparison of direction search process (a) existing car navigation system (b) proposed system (a)

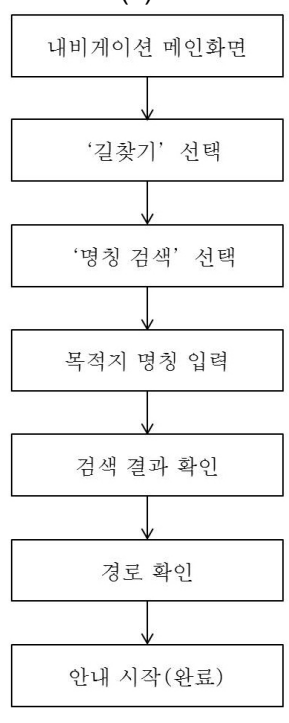

(b)

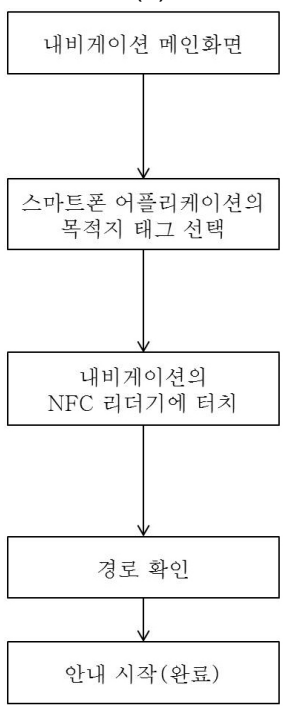

교통안전공단의 시험 결과 기존의 차량용 내비게이 션의 작동에는 10 30초가 소요되는 것으로 조사되었 고[18], 자체 실험 결과 내비게이션으로 목적지를 검색 하고 경로 안내를 받기까지 평균 15 회의 터치를 해야 한다. 이와 같은 기존의 내비게이션 시스템과 본 논문 에서 구현한 어플리케이션을 사용해 경로 안내를 받기 위해 각각 몇 번의 터치가 필요한지 표 3 을 통해 비교하 였다. 표 3을 통해 본 논문에서 구현한 어플리케이션을 사용하면 내비게이션 조작 과정에서의 터치를 최소화 할 수 있다는 것을 확인할 수 있다. 최근 출시된 내비게 이션들은 대부분 초성검색 기능을 제공한다. 하지만 정 확한 명칭이 아닌 초성으로 검색할 경우 검색된 목록들 중에서 원하는 목적지를 찾아서 선택해야 한다. 초성검 색을 사용하지 않은 경우와 비교했을 때 원하는 목적지 를 찾는 과정에서 오히려 더 많은 시간이 소요되는 경 우가 있으며, 운전에 대한 집중력이 분산되기 때문에 초성검색은 실험에서 제외하였다. 
표 3. 내비게이션 종류별 터치 횟수 비교 (검색어 : 천안역) Table. 3 The number of inputs required for searching '천안역'

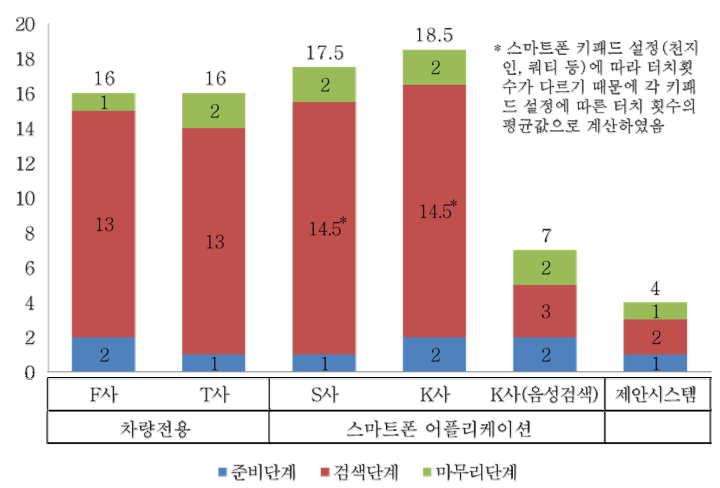

본 논문에서 제안한 시스템을 활용하였을 때 최대 18.5 회, 최소 7회가 필요했던 평균 터치횟수를 4회까지 줄여 적게는 $43 \%$ 에서 최대 $78 \%$ 까지 개선 가능하다. 또 한 각 단계별로 1 회의 터치만을 필요로 하기 때문에 터 치 횟수가 최소로 줄었다는 것이 본 시스템의 강점이다. 이 시스템을 통해 운전 중 내비게이션 조작 과정을 최 소한으로 줄여 집중력 분산으로 인한 교통사고 예방으 로도 이어질 수 있을 것이다.

\section{V. 결 론}

기존의 차량용 내비게이션 단말기는 이용자가 직접 찾고자 하는 목적지의 주소나 전화번호, 명칭 등을 입 력해서 이용자의 위치로부터 목적지까지의 경로를 지 도의 형태로 표시해주는 기능을 한다. 하지만 내비게이 션 단말기 터치화면의 민감도가 낮아서 목적지 입력 시 정확도와 입력속도가 크게 떨어진다. 따라서 목적지를 입력하고 검색하는 과정이 다소 복잡하고 불편하다는 단점을 가지고 있다.

본 연구에서 구현된 시스템은 내비게이션 단말기의 조작 과정을 단순한 NFC로 대체하였다. 이에 따라, 사 용자는 스마트폰을 NFC 리더기에 터치하는 간단한 동 작만으로 목적지의 정보를 입력할 수 있다. 또한, 내비 게이션 단말기의 복잡한 조작 과정으로 인한 운전자의 집중력 분산을 최소화하여 도로주행 시 교통사고 발생
의 위험을 대폭 줄일 수 있다는 장점을 갖는다. 이 시스 템을 통해 운전자는 간편하게 내비게이션의 경로 안내 를 받을 수 있고, 내비게이션 사용 시의 편리성과 안전 성을 동시에 증가시킬 수 있다.

\section{REFERENCES}

[1] Gim Gyeongsik, Shin Junho, "NFC Technology and Certification Trend," TTA Journal No. 133, pp. 132-136, 2011.

[2] NFC Forum. NFC Forum Specification Architecture [Internet]. Available: http://nfc-forum.org/our-work/ specifications-and-application-documents/specifications/.

[3] Chulhoi Koo, Wonkyu Lee, Chungho Park, Youngkon Kim, "Mobile NFC Payment System for Realizing Unmanned Market," in Proceeding of the Korean Institute of Information Scientists and Engineers Conference, vol. 38, no. 2, pp. 81-84, 2011.

[4] Kim Sung Yun, Kim Eun, Lee Yun Seok, Jung Min Su, "A Design of Home Shopping Payment System using a NFC," In Proceeding of the Korean Institute of Communications and Information Sciences Conference, pp. 175-176, 2013.

[5] T. Plos, M. Hutter, M. Feldhofer, M. Stiglic, and F. Cavaliere, "Security-Enabled Near-Field Communication Tag With Flexible Architecture Supporting Asymmetric Cryptography, "IEEE Trans, Very Large Scale Integration (VLSI) Systems, vol. 21, no.11, pp. 1965-1974, 2013.

[6] Kim Young Sub, Lee Yun Seok, Kim Eun, Jung Min Su, "Design for electronic business card system supported dynamic updating," in Proceeding of the Korean Institute of Information Scientists and Engineers Conference, pp. 441-442, 2013.

[ 7] Dongwon Choi, Soonmook Jeong, Seunghyun Yoon, Kyungmin Lee, Seongjin Cho, Kiljae Kim, Key Ho Kwon, Jae Wook Jeon, "Data Sharing Service using NFC Application in the Cloud Environment," In Proceeding of the Human Computer Interaction Korea Conference, pp. 275-277, 2012.

[ 8] MoonSoo Jang, Mikyoung Moon, "Fitness Centers Management System Using NFC," In Proceeding of the Korea Society of Computer Information Conference, Vol. 20, No. 2, pp. 69-70, 2012.

[9] EunMi Lee, OkKyung Choi, HongJin Yeh, "A Mobile Printing System based on User Authentication using NFC 
Tag," in Proceeding of the Korean Institute of Information Scientists and Engineers Conference, vol. 35, no. 1, pp. 41-43, 2012.

[10] Kwang-Myung Kim, Sae-Joon Ha, Seung-Jin Moon, "Car Smart Key Using NFC Proposition," In Proceeding of the Korean Institute of Communications and Information Sciences Conference, pp. 388-389, 2012.

[11] Dae-Soo Cho, "An Implementation of Attendance Management System using NFC," Journal of the Korea Institute of Information and Communication Engineering, Vol. 17, No. 7, pp. 1639-1644, 2013.

[12] Min-Gu Lee, Dong-Wan Kim, Jin-Soo Sohn, "Active Authentication Method using NFC," Journal of the Korean Institute of Communications and Information Sciences, Vol. 37, No. 2, pp. 140-156, 2012.

[13] Baek Jonghyeon, Yeom Hongyeol, "Mobile Service security threats and countermeasures based on NFC," Journal of the Korea Institute of Information Security \& Cryptology, Vol. 23, No. 2, pp. 55-65, 2013.

[14] E. Husni, S. Purwantoro, "Shopping application system with Near Field Communication (NFC) based on Android ," In Proceeding of the System Engineering and Technology 2012 International Conference on, pp. 1-6, 2012.

[15] Gim Seonpyo, Go Seongyong, Jeong Haeju, "Introduction of Near Field Communication(NFC) and Application Method for the Military," Introduction of the Monthly Magazine : Defense \& Technology 409, Korea Defense Industry Association, pp. 106-113, 2013.

[16] Jo Miyeong, Gim Gicheon, "A study on Market Trend and Activiation Plan of NFC," Information \& Communications Magazine, The Korean Institute of Communications and Information Sciences, Vol. 29, No. 6, pp. 58-66, 2012.

[17] Se Won Oh, "Mobile RFID Technology Standardization Activities and Strategy," Journal of the Korean Institute of Communications and Information Sciences, Vol. 36, No. 12, pp. 1698-1707, 2011.

[18] Ministry of Land, Infrastructure and Transport, operational vehicle has potential accident factor of about $75.7 \%$ [Internet]. Available: http://www.mltm.go.kr/USR/NEWS $/ \mathrm{m} \_71 /$ dtl.jsp?id=95071013.

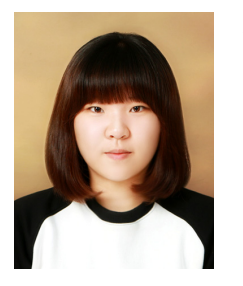

\section{신예진(Yejin Shin)}

2014년 2월 한국기술교육대학교 전기전자통신공학부 (공학사)

2014년 2월 현재 한국기술교육대학교 전기전자통신공학과 석사과정

※관심분야 : 무선통신, RFID/USN

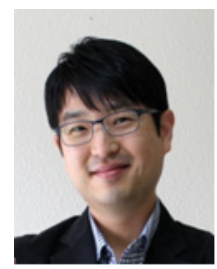

\section{설순욱(Soonuk Seol)}

1998년 2월 한국기술교육대학교 정보통신공학과 (공학사)

2000년 2월 한국과학기술원 정보통신공학과 (공학석사)

2004년 2월 한국과학기술원 정보통신공학과 (공학박사)

1998년 3월 1999년 10월 한국전자통신연구원 위촉연구원

2004년 2월 2012년 2월 KT 종합기술원 차장

2012년 3월 현재 한국기술교육대학교 전기전자통신공학부 조교수

※관심분야 : 모바일 VolP/IPTV, 유무선 네트워크 QOS, 프로토콜 공학 